\title{
Lipoabdominoplasty technique
}

\author{
Alan Matarasso ${ }^{1,2}$, Simrat Suri ${ }^{3}$, Michael J. Stein $^{1,2}$ \\ 'Department of Plastic and Reconstructive Surgery, Lenox Hill Hospital, New York, NY 10065, USA. \\ ${ }^{2}$ Manhattan Eye Ear and Throat Hospital, New York, NY 10065, USA. \\ ${ }^{3}$ Donald and Barbara Zucker School of Medicine, Hempstead, NY 11549, USA.
}

Correspondence to: Dr. Michael J. Stein, Department of Plastic and Reconstructive Surgery, Lenox Hill Hospital, 100 E 77th St, New York, NY 10075, USA. E-mail: mike.stein@nychhc.org

How to cite this article: Matarasso A, Suri S, Stein MJ. Lipoabdominoplasty technique. Plast Aesthet Res 2021;8:57. https://dx.doi.org/10.20517/2347-9264.2021.37

Received: 19 Apr 2021 First Decision: 19 Jul 2021 Revised: 26 Jul 2021 Accepted: 6 Sep 2021 Published: 5 Nov 2021

Academic Editor: Karol A. Gutowski Copy Editor: Xi-Jun Chen Production Editor: Xi-Jun Chen

\begin{abstract}
Abdominoplasty techniques have evolved with our improved understanding of vascular anatomy, tissue mechanics, and patient preferences. As a result, today, surgeons are well equipped with an armamentarium of evidence-based techniques and adjuncts that safely and effectively address abdominal lipodystrophy, skin flaccidity, and myofascial laxity. Abdominoplasty is now one of the most common procedures performed by plastic surgeons in the United States, with rates projected to increase with the growing popularity of bariatric surgery, an aging population, and increasing motivation from a generation of patients who have undergone liposuction alone. The present article reviews the authors' current technique.
\end{abstract}

Keywords: Abdominoplasty, lipoabdominoplasty, body contouring, surgical technique

\section{INTRODUCTION}

The goal of an abdominoplasty is the aesthetic improvement of lipodystrophy, skin excess, and myofascial diastasis. Each patient presents to the surgeon with a unique body habitus and varying degree of "anatomic pathology", for which the surgeon tailors their technique accordingly. Six decades of technical refinement, the introduction of new technologies, and increased patient demand have made abdominoplasty one of the most common procedures in plastic surgery today with demonstrable safety, reliability, and reproducibility. 
Today, surgeons can rely on a broad range of evidence-based abdominoplasty techniques which are safe, effective, and reproducible. The principle of tailoring the surgical approach to the specific "anatomic pathology" must not be understated. In the late 1980's a 4-stage classification system matched the degree of adiposity and skin excess to the optimal surgical technique ${ }^{[1-4]}$ [Table 1]. Over thirty years later, this algorithm remains the most commonly used for its practicality and simplicity. However, today a variety of innovations can be used in select patients to supplement this algorithm ${ }^{[5,6]}$. For example, anatomical definition may be improved with superficial liposculpting, the efficiency of fat extraction may be improved with radio and laser frequency liposuction technologies, high lateral tension closures can improve flank contour, and fleur-de-lis or 270-degree abdominoplasties can optimize contour in massive weight loss patients. As technology advances and new techniques continue to emerge, it remains clear that the technical execution of these operations remains patient-specific and tailored to the specific anatomic presentation.

Herein, the authors' current surgical technique is outlined, representing the culmination of over 30 years of experience.

\section{PREOPERATIVE MARKINGS}

A vertical line is drawn using the anterior vaginal commissure as a reference for the true midline, irrespective of the umbilicus position. Two parallel lines are then marked over the linea semilunaris bilaterally. Incorporating the umbilicus into the midline marking is a common error, increasing the risk for umbilical malposition, as it has been demonstrated that it is a midline structure in less than $2 \%$ of cases $^{[7]}$. The patient then sits, and the extent of the skin creases are marked out laterally with a dot to mark the apex of the skin resection bilaterally [Figure $1 \mathrm{~A}$ ]. Next, with the patient providing upward traction on the suprapubic skin, a horizontal line is marked, 5-7 cm superior to the superior labial commissure, marking the inferior resection margin. Male patients whose undergarments are positioned higher and do not require accentuation of the waist tolerate higher incisions, which can be marked based on their undergarment height ${ }^{[8]}$. Lateral extensions are then marked with a stencil for symmetry [Figure 1B], the inclination of which is contingent upon the shape of the pelvis. In the anthropoid pelvis and/or a long-waisted patient, these tend to diverge more acutely than in a gynecoid pelvis or short-waisted patient. The key is to keep the incision parallel and superior to the inguinal ligament in order to provide thicker, more robust soft tissue for closure, as well as mitigate the risk of injuring the lateral femoral cutaneous nerve of the thigh, which is located along the inguinal ligament in $80 \%$ of cases and 3-7 cm medial to the Anterior Superior Iliac Spine $(A S I S)^{[9,10]}$. Finally, the upper incision joins a point $1 \mathrm{~cm}$ above the umbilicus to each apex to finalize the ellipse. Intraoperative bed flexion is simulated by having the patient lean forward and performing a pinch test to evaluate closure tension ("The Matarasso Maneuver"). Ultimately, all markings are confirmed intraoperatively after liposuction with the operating room bed in the beach chair position.

It is essential to recognize the presence of hip asymmetry [Figure 2A]. Over $80 \%$ of abdominoplasty candidates have been shown to have hip asymmetry ${ }^{[11]}$, which can have significant implications on final scar placement. Incision design must take these asymmetries into consideration. If ignored and based on the ASIS alone, preoperative markings are symmetric, but final scar placement is not. A preoperative discussion of the hip discrepancies is advised to avoid poor patient satisfaction and mitigate the risk of medicolegal complications. The senior author marks asymmetrically to consider the hip discrepancy and then uses the "crisscross technique" intraoperatively to confirm these markings [Figure $2 \mathrm{~B}$ and $\mathrm{C}$ ]. This involves placing 0 -silk sutures at the vulvar cleft and the xiphoid, grasping the uncut ends with a clamp, and moving them laterally along the incision lines to ascertain symmetry between sides ${ }^{[12]}$. 
Table 1. The lipoabdominoplasty classification system

\begin{tabular}{lllll}
\hline Type & Skin & Fat & Musculofascial system & Treatment \\
\hline I & Minimal laxity & Variable & Minimal diastasis & Suction-assisted lipectomy \\
II & Mild laxity & Variable & Lower diastasis & Mini abdominoplasty \\
III & Moderate laxity & Variable & Lower and upper diastasis & Modified abdominoplasty \\
IV & Severe laxity & Variable & Complete diastasis & Standard abdominoplasty with or without suction lipectomy \\
\hline
\end{tabular}
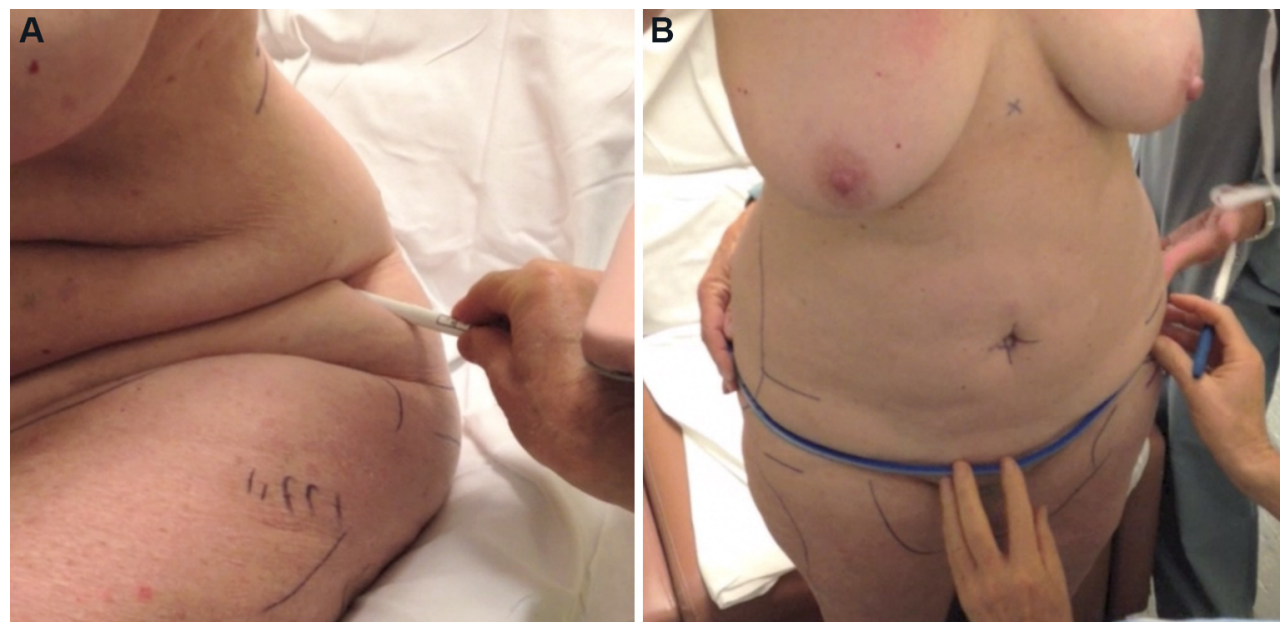

Figure 1. (A) Marking lateral extent of incision in sitting position. (B) Incision stencil.
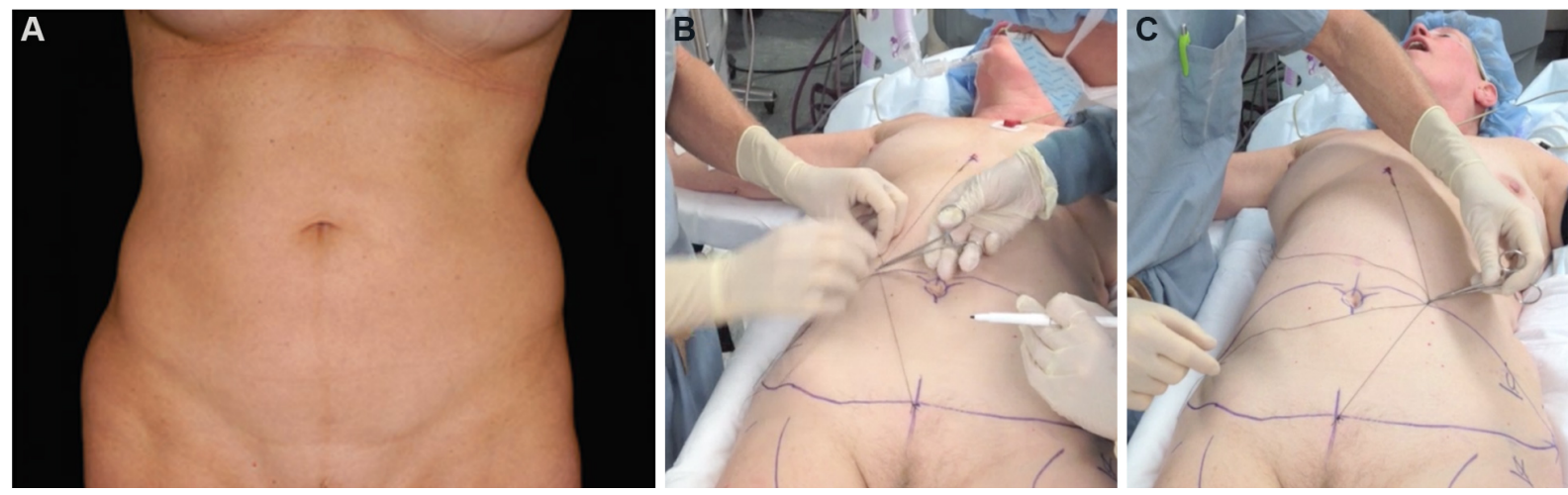

Figure 2. (A) Patient with hip discrepancy. (B, C) Crisscross technique.

Abdominal markings for massive weight loss patients remain challenging. Asymmetric pannus adiposity and weight make marking in the standing position difficult. The authors' practice is to mark these patients lying down. First, the inferior margin is marked as usual, and then one hand retracts the pannus away from the inferolateral markings in the vector that mimics closure tension. With the patient standing, these markings may appear asymmetric due to the heterogeneity in the pannus's weight under gravity, yet the surgeon must be reminded to treat the patient, not the photograph, and remain committed to their original markings. 


\section{ANESTHESIA, POSITIONING AND ENHANCED RECOVERY AFTER SURGERY PROTOCOL}

Abdominoplasty remains an ambulatory procedure performed in an accredited facility in the presence of an anesthesiologist who performs spontaneous ventilation general anesthesia or spinal/epidural anesthesia. The surgical bed beach chair position is confirmed, and the patient is positioned at the bed break for optimal hip flexion intraoperatively. Boney prominences are padded, the arms are immobilized with Kerlix, and sequential compression devices and Foley catheters are placed.

Enhanced Recovery After Surgery (ERAS) protocols are evidence-based perioperative directives that reduce (or eliminate) narcotic consumption, improve patient satisfaction and accelerate recovery after plastic surgery procedures ${ }^{[13,14]}$. They are particularly important following abdominoplasty, as this is the body contouring procedure with the greatest discomfort and highest risk of a venous thromboembolic event compared to any other plastic surgery procedure. ERAS protocols work to mitigate this risk by facilitating earlier mobilization and return to activities. Preoperatively, our ERAS protocol [Table 2] includes counseling, nutrition optimization, and chlorhexidine rinses three days preoperatively. Massive weight loss patients warrant particular attention, commonly requiring a multidisciplinary workup including a hematologist, dietician and social worker ${ }^{[15-18]}$. Multimodal analgesic and antinauseant protocols consist of acetaminophen, celecoxib, and gabapentin three days before surgery, and aprepitant (Emend) $2 \mathrm{~h}$ before the surgery, $1 \mathrm{~g}$ IV infusion of acetaminophen over $30 \mathrm{~min}$ at the time of incision, and $4 \mathrm{mg}$ of Ondansetron before extubation. If the patient has a history of postoperative nausea, vomiting, or motion sickness, we avoid fentanyl and nitrous oxide intraoperatively and place a scopolamine patch.

Intraoperatively, anesthesiologists limit opioid administration and add $10 \mathrm{mg}$ metoclopramide, $10 \mathrm{mg}$ dexamethasone, and $8 \mathrm{mg}$ ondansetron solution to the IV fluid bag. Surgeon-administered anesthesia consists of tumescence ( $1 \mathrm{~L}$ of Ringer's lactate, $200 \mathrm{mg}$ lidocaine, $1 \mathrm{mg}$ of epinephrine) infiltration at the start of the case, in addition to a Transverse Abdominus Pane (TAP) blocks with $133 \mathrm{mg}$ of Liposomal Bupivicaine (Exaparel, Pacira Pharmaceuticals, SanDiego, CA) and $25 \mathrm{mg}$ Bupivicaine with epinephrine mixture in $80 \mathrm{~mL}$ of normal saline).

Postoperatively, early oral intake ${ }^{[19]}$ is encouraged, and patients are discharged with a 7-day course of a stool softener to limit strain, in addition to Acetaminophen, celecoxib, gabapentin, and oxycodone, the latter of which the patient is instructed only to use during a pain crisis. Using this standardized protocol, our experience, similar to others ${ }^{[20]}$, is a trend towards less postoperative pain, reduced opioid consumption, and decreased reports of nausea, vomiting, and constipation. In our experience, the use of Exparel has been the most effective intervention, eliminating post-operative opioid consumption in most patients. Patients are encouraged to shower postoperative day 1 and wear an abdominal binder starting post-operative day 3.

An aggressive mobilization protocol commences upon arrival at home. Patients are instructed to ambulate every $2 \mathrm{~h}$ for $10 \mathrm{~min}$ and wear compression stockings while asleep. The senior author's practice considers perioperative anticoagulation when the 2005 Caprini risk stratification score is greater than 7 . In these patients, we advise asking about miscarriage and abortion history and offer hematology testing and preoperative lower extremity ultrasound. These patients received enoxaparin $8 \mathrm{~h}$ after surgery and $40 \mathrm{mEq}$ daily thereafter for a duration determined by their specific risk profile. For example, patients heterozygous of factor V Leiden are anticoagulated for 30 days, while patients with a history of DVT for 14 days. With a venous thromboembolism risk 18 times greater in abdominoplasty compared to any other plastic surgery procedure, the consideration of perioperative anticoagulation should not be taken lightly. 
Table 2. Abdominoplasty Enhanced Recovery After Surgery protocol

\begin{tabular}{|c|c|c|}
\hline Preoperative & Intraoperative & Postoperative \\
\hline \multicolumn{3}{|l|}{ Analgesia } \\
\hline Celecoxib 400 mg (3 days preop reg) & $\begin{array}{l}\text { Acetaminophen } 1 \mathrm{~g} \text { IV infusion over } 30 \mathrm{~min} \text { at the time of } \\
\text { incision }\end{array}$ & $\begin{array}{l}\text { Celecoxib } 400 \mathrm{mg} \\
\text { (7 days postop reg) }\end{array}$ \\
\hline Gabapentin 300 mg (3 days preop reg) & Avoidance of opioid administration by anesthesiologists & $\begin{array}{l}\text { Gabapentin } 300 \mathrm{mg} \\
\text { (7 days postop reg) }\end{array}$ \\
\hline \multirow[t]{2}{*}{ Acetaminophen 650 mg (3 days preop reg) } & $\begin{array}{l}\text { Tumescent infiltration ( } 1 \mathrm{~L} \text { Ringer's lactate, } 200 \mathrm{mg} \text { of } \\
\text { lidocaine, } 1 \mathrm{mg} \text { epinephrine) }\end{array}$ & $\begin{array}{l}\text { Acetaminophen } 650 \mathrm{mg} \\
\text { (7 days postop reg) }\end{array}$ \\
\hline & $\begin{array}{l}\text { Bilateral TAP blocks ( } 133 \mathrm{mg} \text { of Exaparel and } 25 \mathrm{mg} \\
\text { Marcaine with epinephrine mixed in } 80 \mathrm{~mL} \text { of normal } \\
\text { saline }\end{array}$ & $\begin{array}{l}\text { Oxycodone } 10 \mathrm{mg} \\
\text { (30 tabs prn) }\end{array}$ \\
\hline \multicolumn{3}{|l|}{ Antiemetic } \\
\hline Emend $80 \mathrm{mg}$ ( $2 \mathrm{~h}$ before surgery) & Ondansetron $4 \mathrm{mg}$ push & Scopolamine patch \\
\hline $\begin{array}{l}10 \mathrm{mg} \text { metoclopramide, } 10 \mathrm{mg} \text { dexamethasone, and } \\
8 \mathrm{mg} \text { ondansetron solution to the initial IV fluid bag }\end{array}$ & & $\begin{array}{l}\text { Early oral feeding and } \\
\text { hydration }\end{array}$ \\
\hline \multicolumn{3}{|l|}{ DVT Prophylaxis } \\
\hline \multirow[t]{3}{*}{ Preoperative warming } & Daltaparin $5000 \mathrm{U}$ at start of case & $\begin{array}{l}\text { Early mobilization } \\
(10 \text { min walk every } 2 \mathrm{~h})\end{array}$ \\
\hline & Sequential compression devices & $\begin{array}{l}\text { Ankle wiggles and knee } \\
\text { bends while in bed }\end{array}$ \\
\hline & Limit operative time & $\begin{array}{l}\text { Compression stocks while } \\
\text { asleep }\end{array}$ \\
\hline
\end{tabular}

\section{LIPOSUCTION}

Liposuction of abdominal aesthetic units ${ }^{[21,22]}$ continues to play a central role in achieving an aesthetic result following abdominoplasty. Many new adjuncts ${ }^{[23]}$ have emerged, including ultrasound, laser, and radiofrequency-assisted devices, all of which can be employed safely and effectively in the context of lipoabdominoplasty. However, the senior author continues to use power-assisted liposuction with superwet tumescent anesthesia exclusively ${ }^{[24]}$. One liter of tumescent solution is injected into the flanks, upper abdomen and suprapubic area keeping in mind the maximal dose of tumescent and epinephrine of $35 \mathrm{mg} / \mathrm{kg}-55 \mathrm{mg} / \mathrm{kg}$ and $0.7 \mathrm{mg} / \mathrm{kg}$, respectively ${ }^{[25]}$. Injecting the central abdomen is limited and makes use of electrocautery cumbersome. Liposuction then proceeds in a graded fashion with the knowledge of abdominal flap vascularity [Figure 3]. In select healthy patients with lower BMI and good skin quality, superficial liposuction is performed over the linea alba and semilunaris markings to improve anatomic definition. The remaining liposuction is performed deep to prevent contour irregularities, the most common complication of abdominal liposuction ${ }^{[26]}$.

\section{ABDOMINOPLASTY}

When concomitant breast surgery is performed with an abdominoplasty, our practice is to operate on the breasts first. However, in our experience, the order does not necessarily matter as the breasts are anatomically distinct from the abdominoplasty flap pull, and closure does not affect intramammary fold position $^{[27]}$. In addition, abdominoplasty is performed in the flexed position rendering it difficult to do additional surgery afterward.

The procedure begins with incising the umbilicus while an assistant holds retraction with single hooks. Metzenbaum scissors are then used to free the umbilical stock from the abdominoplasty flap. Next, the superior marking is incised, and dissection is carried down to the fascia with a 20-blade scalpel. Monopolar cautery is then used to create a narrow tunnel up the xiphoid, preserving perforators from the epigastric arteries medially and intercostal arteries laterally [Figure 4]. Next, the table is flexed to ascertain that the 


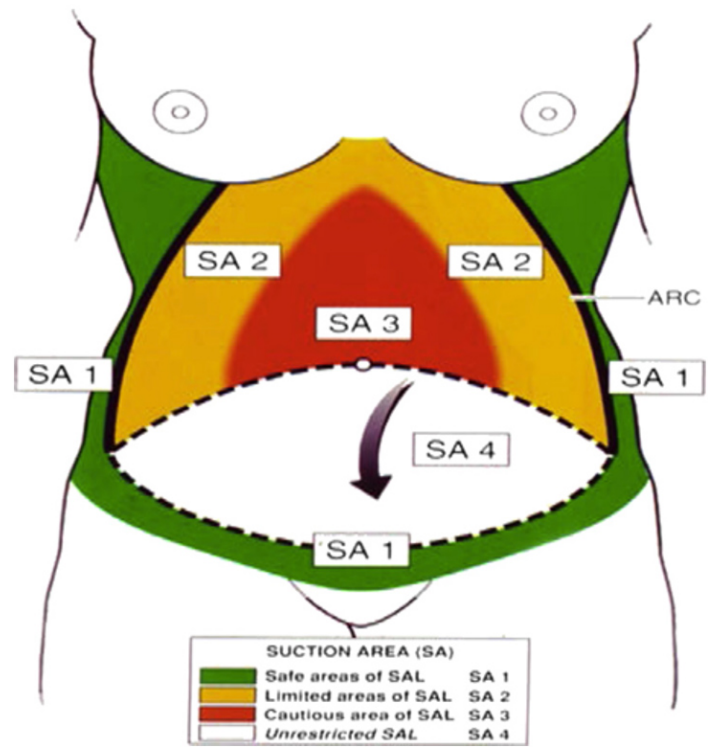

Figure 3. A graded approach to liposuction zones (Matarasso, 2010).<smiles>[R][V]</smiles>

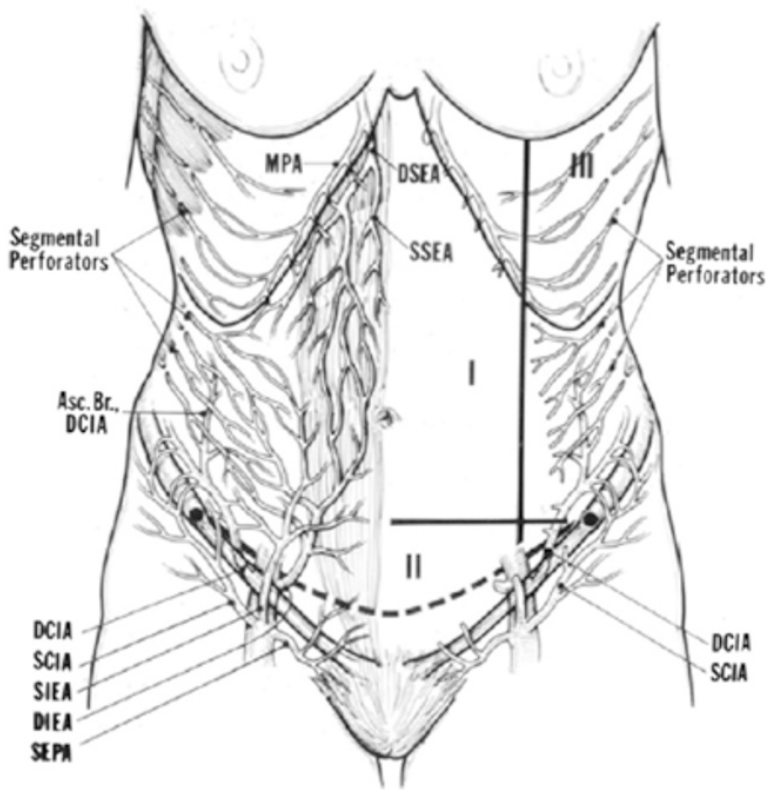

Figure 4. Huger zones of abdominoplasty flap vascularity (Matarasso, 2014).

upper flap meets the proposed inferior incision and, once confirmed, the inferior marking is made, and the pannus is excised with a 20-blade scalpel while an assistant achieves hemostasis with an insulated forceps and monopolar cautery. It is worth noting that the inferior incision is performed cautiously in massive weight loss patients as the large, asymmetric pannus and ptotic suprapubic fat can distort anatomy, bringing the spermatochord, lymphatic tissues, and vessels into the surgical field. 
Following pannus removal, a plastic ocular conformer is sutured to the umbilical stock to facilitate easy retrieval following closure ${ }^{[28]}$. It is worth noting that palpating the ocular conformer is indicative of the vertical position of the umbilicus, but the surgeon's original meridian dictates the horizontal position following closure.

Before diastasis repair, we examine for signs of an umbilical hernia. If a hernia is present, it should be repaired prior to midline plication, and this is routinely discussed with the patient preoperatively and included in the consent process. It is our practice to repair small umbilical hernias with a minimal access Ventralex mesh ${ }^{[29]}$, while larger ones with bioresorbable (Phasix) underlay mesh.

The diastasis is then marked, and a running, double-stranded, 0 -Nylon is run above and below the umbilicus with the knots buried. An additional layer of interrupted nylon sutures is placed for additional strength. An assessment of the fascial tension and the waistline then determines whether additional rows of facial plications are required lateral to the umbilicus. In thin patients that desire a narrower waistline, in addition to aggressive flank liposuction, we perform horizontal waistline sutures at the level of the umbilicus $^{[30]}$. We make sure to counsel patients preoperatively of potential changes in the umbilicus $\operatorname{position}^{[31]}$.

Following final hemostasis, the fascia is bathed in a human fibrinogen sealant (VistaSeal ${ }^{\mathrm{TM}}$ ) to promote flap adhesion. The abdominoplasty flap is then tailor-tacked into place with staples. Final closure is performed using a double layer of barbed sutures ${ }^{[32]}$. The deep layer involves a large bite of Scarpa's fascia and dermis with 2-0 PDO Quill. One suture is typically required for each half of the wound. This is followed by a second subcuticular layer of 3-0 PDO Quill, which provides closure of the skin and typically requires a single suture for each half of the abdomen. Minor skin bunching and contour irregularities after closure are common and settle in the postoperative period. The last step is to mark a $2.5 \mathrm{~cm}$ inverted $\mathrm{V}$ incision over the central meridian at the vertical level of the palpated conformer. A $1 \mathrm{~cm}$ donut of fat is trimmed on the overlying abdominoplasty flap to improve contour, the conformer is removed, and the umbilicus is inset with 3-0 deep dermal PDS suture followed by simple interrupted 4-0 nylon sutures.

While progressive tension sutures have been used effectively to decrease seroma rates and obviate the use of drains, we commonly place two 14-French Jackson Pratt drains (and four in massive weight loss patients) exteriorized and sutured into the incision to decrease scar burden. While advocates of the drainless abdominoplasty report reduced pain and discomfort, the authors' experience is that most postoperative discomfort comes from fascial plication rather than drain placement, and the role of drains in decreasing postoperative swelling accelerating recovery cannot be understated. In addition, a new internal suction system has recently emerged that obviates the need for JP drains while simultaneously reducing swelling and seroma rates. The Interi suction device [Figure 5] is a single-use, wearable suction appliance with multiple internal drains exiting through a single exit site. The continuous suction provides early and sustained tissue apposition, effectively obliterating the dead space and actively draining excess fluid rather than relying on gravity and bulb suction. This technology also benefits by reducing the level of care patients require to empty and change their drains at home.

Steri strips or Prineo-dermabond (Ethicon, Somerville, New Jersey) tape can then be applied, with the latter reserved for patients with no history of skin sensitivity. Finally, an abdominal binder is sent home with the patient, and they are instructed to start wearing it continuously post-operative day 3 for four weeks [Figure 6]. 

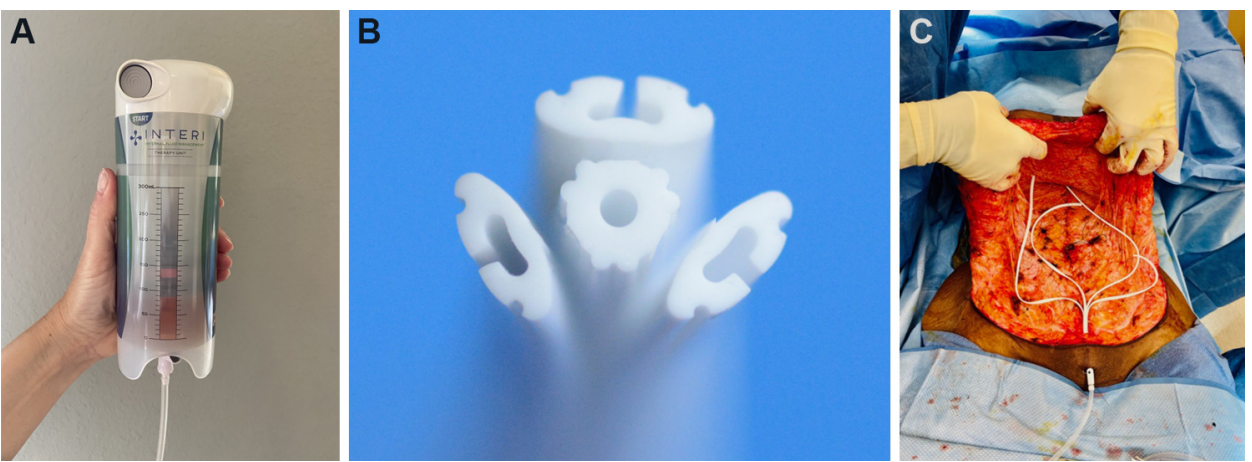

Figure 5. (A, B, C) The Interi internal suction system: ideal for obliterating abdominal dead space, decreasing seroma rates, and reducing patient-directed maintenance.
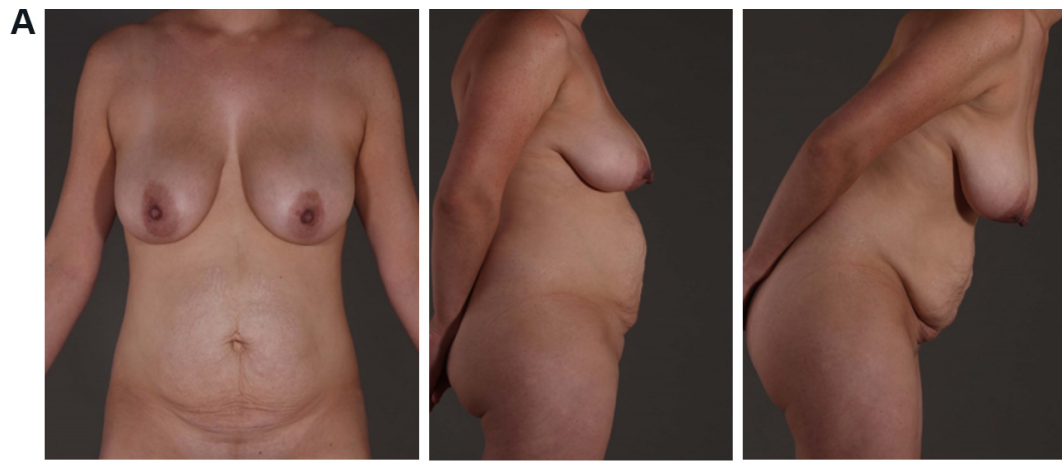

B
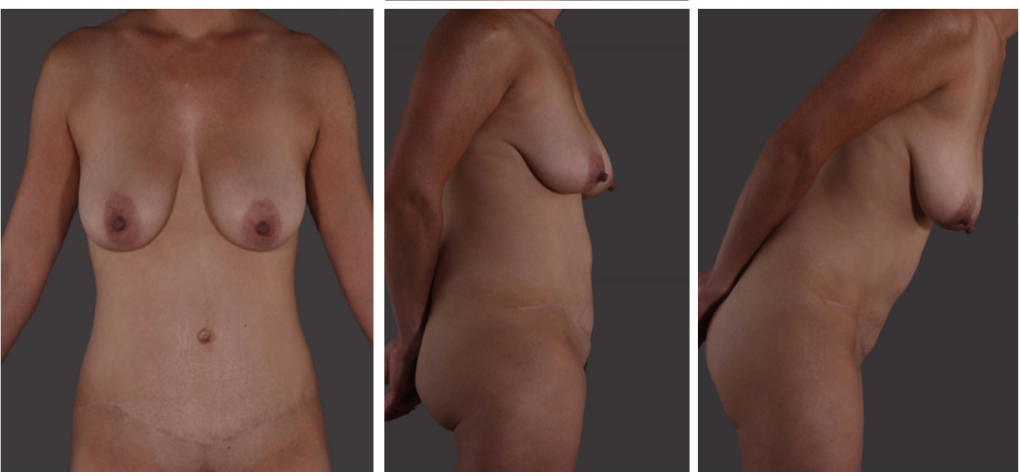

Figure 6. Patient 1: (A) preoperative. (B) Postoperative. A 38-year-old gravid 2, female abdominoplasty.

\section{SECONDARY ABDOMINOPLASTY}

Secondary abdominoplasty is becoming increasingly common, especially in recurrence following "mini" or short scar abdominoplasties. While we have shown that secondary surgery can be performed with a complication rate comparable to that of primary surgery ${ }^{[3,343]}$, surgeons must note the treatment of the umbilicus during the original surgery. Patient with prior umbilical stalk detachment is increasingly common, either in the context of previous umbilical hernia repair or during a mini-abdominoplasty where the umbilicus is "floated". In these circumstances, the umbilical delay is a valuable maneuver to decrease the risk of umbilical necrosis ${ }^{[35]}$. 


\section{CONCLUSION}

Abdominoplasty remains one of the most commonly performed procedures by plastic surgeons in the United States, and the patient population is continuously growing. However, as techniques continue to evolve and technological adjuncts continue to innovate, the surgeon is advised to revert to the tried and true foundation which has made the surgery safe and effective for over sixty years.

\section{DECLARATIONS}

\section{Authors' contributions}

Made substantial contributions to conception and design of the study: Matarasso A, Stein MJ

Assisted with conception and design of the study: Suri S

\section{Availability of data and materials}

Not applicable.

\section{Financial support and sponsorship}

None.

\section{Conflicts of interest}

All authors declared that there are no conflicts of interest.

\section{Ethical approval and consent to participate}

Not applicable.

\section{Consent for publication}

Consent for photography was obtained by operating surgeon Dr. Alan Matarasso.

\section{Copyright}

(c) The Author(s) 2021.

\section{REFERENCES}

1. Matarasso A. Abdominolipoplasty. Clin Plast Surg 1989;16:289-303. PubMed

2. Matarasso A. Abdominolipoplasty: a system of classification and treatment for combined abdominoplasty and suction-assisted lipectomy. Aesthetic Plast Surg 1991;15:111-21. DOI PubMed

3. Matarasso A, Matarasso DM, Matarasso EJ. Abdominoplasty: classic principles and technique. Clin Plast Surg 2014;41:655-72. DOI PubMed

4. Hughes CE 3rd, Lockwood TE, Baroudi R, Matarasso A. Abdominoplasty. Aesthet Surg J 2002;22:465-73. DOI PubMed

5. O'Kelly N, Nguyen K, Gibstein A, Bradley JP, Tanna N, Matarasso A. Standards and trends in lipoabdominoplasty. Plast Reconstr Surg Glob Open 2020;8:e3144. DOI PubMed PMC

6. Matarasso A, Zins JE. Abdominoplasty: state-of-the-art. Clin Plast Surg 2020;47:ix-X. DOI PubMed

7. Rohrich RJ, Sorokin ES, Brown SA, Gibby DL. Is the umbilicus truly midline? Plast Reconstr Surg 2003;112:259-63; discussion 2645. DOI PubMed

8. Matarasso A. The male abdominoplasty. Clin Plast Surg 2004;31:555-69, v-vi. DOI PubMed

9. Chowdhry S, Davis J, Boyd T, et al. Safe tummy tuck: anatomy and strategy to avoid injury to the lateral femoral cutaneous nerve during abdominoplasty. Eplasty 2015;15:e22. PubMed PMC

10. Grothaus MC, Holt M, Mekhail AO, Ebraheim NA, Yeasting RA. Lateral femoral cutaneous nerve: an anatomic study. Clin Orthop Relat Res 2005;(437):164-8. DOI PubMed

11. Maia M, Shikowitz-Behr L, Matarasso A. Hip asymmetry: implications in body contouring surgery. Plast Reconstr Surg 2019;143:513e-7e. DOI PubMed

12. Matarasso A. Traditional abdominoplasty. Clin Plast Surg 2010;37:415-37. DOI PubMed

13. Constantine FC, Matarasso A. Putting it all together: recommendations for improving pain management in body contouring. Plast Reconstr Surg 2014;134:113S-9S. DOI PubMed

14. Bartlett EL, Zavlin D, Friedman JD, Abdollahi A, Rappaport NH. Enhanced recovery after surgery: the plastic surgery paradigm shift. Aesthet Surg J 2018;38:676-85. DOI PubMed

15. Matarasso A, Aly A, Hurwitz DJ, Lockwood TE. Body contouring after massive weight loss. Aesthet Surg J 2004;24:452-63. DOI 
PubMed

16. Matarasso A, Roslin MS, Kurian M; Plastic Surgery Educational Foundation Technology Assessment Committee. Bariatric surgery: an overview of obesity surgery. Plast Reconstr Surg 2007;119:1357-62. DOI PubMed

17. Matarasso A. Bariatric plastic surgery. Aesthet Surg J 2003;23:188-9. DOI PubMed

18. Matarasso A. A "brave new world" for bariatric surgery? Aesthet Surg J 2006;26:697-8. DOI PubMed

19. Jejurikar SS, Orseck MJ, Matarasso A. Reevaluating resumption of oral intake after abdominoplasty. Aesthet Surg J 2007;27:233-8. DOI PubMed

20. Morales R Jr, Mentz H 3rd, Newall G, Patronella C, Masters O 3rd. Use of abdominal field block injections with liposomal bupivicaine to control postoperative pain after abdominoplasty. Aesthet Surg $J$ 2013;33:1148-53. DOI PubMed

21. Matarasso A, Wallach SG. Abdominal contour surgery: treating all aesthetic units, including the mons pubis. Aesthet Surg $J$ 2001;21:111-9. DOI PubMed

22. Matarasso A, Matarasso SL. When does your liposuction patient require an abdominoplasty? Dermatol Surg 1997;23:1151-60. DOI PubMed

23. Shridharani SM, Broyles JM, Matarasso A. Liposuction devices: technology update. Med Devices (Auckl) 2014;7:241-51. DOI PubMed PMC

24. Matarasso A. Superwet anesthesia redefines large-volume liposuction. Aesthet Surg J 1997;17:358-64. DOI PubMed

25. Matarasso A, Levine SM. Evidence-based medicine: liposuction. Plast Reconstr Surg 2013;132:1697-705. DOI PubMed

26. Matarasso A, Swift RW, Rankin M. Abdominoplasty and abdominal contour surgery: a national plastic surgery survey. Plast Reconstr Surg 2006;117:1797-808. DOI PubMed

27. Matarasso A, Smith DM. Combined breast surgery and abdominoplasty: strategies for success. Plast Reconstr Surg 2015;135:849e60e. DOI PubMed

28. Matarasso A, Matarasso DM, Matarasso EJ. Invited commentary of "concepts in navel aesthetic: a comprehensive surface anatomy analysis". Aesthetic Plast Surg 2015;39:51-2. DOI PubMed

29. Neinstein RM, Matarasso A, Abramson DL. Concomitant abdominoplasty and umbilical hernia repair using the Ventralex hernia patch. Plast Reconstr Surg 2015;135:1021-5. DOI PubMed

30. Matarasso A, Smith DM. Strategies for aesthetic reshaping of the postpartum patient. Plast Reconstr Surg 2015;136:245-57. DOI PubMed

31. Chin SH, Martin WJ, Matarasso A. Do waistline and umbilical position really change after abdominoplasty? Plast Reconstr Surg 2010;125:27e-8e. DOI PubMed

32. Matarasso A. Introduction to the barbed sutures supplement: the expanding applications of barbed sutures. Aesthet Surg J 2013;33:7S11S. DOI PubMed

33. Matarasso A, Schneider LF, Barr J. The incidence and management of secondary abdominoplasty and secondary abdominal contour surgery. Plast Reconstr Surg 2014;133:40-50. DOI PubMed

34. Matarasso A, Wallach SG, Rankin M, Galiano RD. Secondary abdominal contour surgery: a review of early and late reoperative surgery. Plast Reconstr Surg 2005;115:627-32. DOI PubMed

35. Dean RA, Dean JA, Matarasso A. Secondary abdominoplasty: management of the umbilicus after prior stalk transection. Plast Reconstr Surg 2019;143:729e-33e. DOI PubMed 